\title{
Accuracy and Precision of the COSMED K5 Portable Analyser
}

\author{
Ismael Perez-Suarez1,2, Marcos Martin-Rincon1,2, Juan José Gonzalez-Henriquez²,3, \\ Chiara Fezzardi', Sergio Perez-Regalado' ${ }^{1}$, Victor Galvan-Alvarez', \\ Julian W. Juan-Habib' ${ }^{1}$, David Morales-Alamo ${ }^{1,2}$ and Jose A. L. Calbet ${ }^{1,2 *}$
}

${ }^{1}$ Department of Physical Education, University of Las Palmas de Gran Canaria, Las Palmas, Spain, ${ }^{2}$ Research Institute in Biomedical and Health Sciences (IUIBS), University of Las Palmas de Gran Canaria, Las Palmas, Spain, ${ }^{3}$ Department of Mathematics, University of Las Palmas de Gran Canaria, Las Palmas, Spain

\section{OPEN ACCESS}

Edited by:

Martin Burtscher,

University of Innsbruck, Austria

Reviewed by:

Hannes Gatterer,

EURAC Research, Italy

Fabien Andre Basset,

Memorial University of Newfoundland

Canada

*Correspondence:

Jose A. L. Calbet

lopezcalbet@gmail.com

Specialty section:

This article was submitted to

Exercise Physiology,

a section of the journal

Frontiers in Physiology

Received: 19 July 2018 Accepted: 22 November 2018 Published: 21 December 2018

Citation:

Perez-Suarez I, Martin-Rincon M, Gonzalez-Henriquez JJ, Fezzardi C, Perez-Regalado S, Galvan-Alvarez V,

Juan-Habib JW, Morales-Alamo D and Calbet JAL (2018) Accuracy and Precision of the COSMED K5

Portable Analyser.

Front. Physiol. 9:1764.

doi: 10.3389/fphys.2018.01764
The main aims of this study were to determine the accuracy of the portable metabolic cart K5 by comparison with a stationary metabolic cart (Vyntus CPX), to check on the validity of Vyntus CPX using a butane combustion test, and to assess the reliability of $\mathrm{K} 5$ during prolonged walks in the field. For validation, measurements were consecutively performed tests with both devices at rest and during submaximal exercise (bicycling) at low $(60 \mathrm{~W})$ and moderate intensities (130-160 W) in 16 volunteers. For the reliability study, 14 subjects were measured two times during prolonged walks ( $13 \mathrm{~km}$, at $5 \mathrm{~km} / \mathrm{h}$ ), with the $\mathrm{K} 5$ set in mixing chamber (Mix) mode. Vyntus measured the stoichiometric $\mathrm{RQ}$ of butane combustion with high accuracy (error $<1.6 \%$ ) and precision (CV $<0.5 \%$ ), at $\mathrm{VO}_{2}$ values between 0.788 and $6.395 \mathrm{~L} / \mathrm{min}$. At rest and $60 \mathrm{~W}$, there was good agreement between Vyntus and $\mathrm{K} 5$ (breath-by-breath, $\mathrm{Bx}$ B) in $\mathrm{VO}_{2}, \mathrm{VCO}_{2}, \mathrm{RER}$, and energy expenditure, while in Mix mode the $\mathrm{K} 5$ overestimated $\mathrm{VO}_{2}$ by 13.4 and $5.8 \%$, respectively. Compared to Vyntus, at moderate intensity the $\mathrm{K} 5$ in $\mathrm{B} \times \mathrm{B}$ mode underestimated $\mathrm{VO}_{2}, \mathrm{VCO}_{2}$, and energy expenditure by $6.6,6.9$, and $6.6 \%$, respectively. However, at this intensity there was an excellent agreement between methods in RER and fat oxidation. In Mix mode, $\mathrm{K} 5$ overestimated $\mathrm{VO}_{2}$ by 5.8 and $4.8 \%$, at $60 \mathrm{~W}$ and the higher intensity, respectively. The $\mathrm{K} 5$ had excellent reliability during the field tests. Total energy expenditure per $\mathrm{Km}$ was determined with a CV for repeated measurements of $4.5 \%(\mathrm{Cl}: 3.2-6.9 \%)$ and a concordance correlation coefficient of 0.91 , similar to the variability in $\mathrm{VO}_{2}$. This high reproducibility was explained by the low variation of $\mathrm{F}_{\mathrm{E}} \mathrm{O}_{2}$ measurements, which had a $\mathrm{CV}$ of $0.9 \%(\mathrm{Cl}: 0.7-1.5 \%)$ combined with a slightly greater variability of $\mathrm{F}_{\mathrm{E}} \mathrm{CO}_{2}, \mathrm{~V}_{\mathrm{E}}, \mathrm{VCO}_{2}$, and $\mathrm{RER}$. In conclusion, the $\mathrm{K} 5$ is an excellent portable metabolic cart which is almost as accurate as a state-of-art stationary metabolic cart, capable of measuring precisely energy expenditure in the field, showing a reliable performance during more than $2 \mathrm{~h}$ of continuous work. At high intensities, the mixing-chamber mode is more accurate than the BxB mode.

Keywords: oxygen uptake, ergometry exercise, metabolic cart, validity, reliability

\section{INTRODUCTION}

Nowadays, oxygen uptake $\left(\mathrm{VO}_{2}\right)$, carbon dioxide production $\left(\mathrm{VCO}_{2}\right)$, and substrate oxidation are mostly determined using stationary metabolic carts. For more specific measurements, particularly in the field, low-weight portable devices are more practical. Essentially, portable metabolic carts allow the measurement of the same variables as stationary metabolic carts with similar or slightly 
lower accuracy; however, the reliability of portable carts seems lower (Brehm et al., 2004; Schrack et al., 2010). Portable devices operate on a breath-by-breath basis $(B \times B)$, requiring the assessment of the tidal volume of each breath and the expiratory fractions of $\mathrm{O}_{2}\left(\mathrm{~F}_{\mathrm{E}} \mathrm{O}_{2}\right)$ and $\mathrm{CO}_{2}\left(\mathrm{~F}_{\mathrm{E}} \mathrm{CO}_{2}\right)$, which must be aligned in time for further calculations, by accounting for the respective delay times (Beaver et al., 1973; Noguchi et al., 1982).

The accuracy of portable and stationary metabolic carts working on a $\mathrm{B} \times \mathrm{B}$ mode, depends to a large extend on the exact determination of the delay times (Overstreet et al., 2017). Most modern stationary metabolic carts have remarkably reduced delay times, and some, like the Vyntus CPX (Jaeger-CareFusion) have delay times for $\mathrm{O}_{2}$ and $\mathrm{CO}_{2}$ analysis almost matching mass spectrometers (Clemensen et al., 1994). Short delay times are necessary to avoid errors in $\mathrm{B} \times \mathrm{B}$ analysis at high respiratory frequencies, i.e., at high exercise intensities (Overstreet et al., 2017). Underestimation of delay time results in overestimations of $\mathrm{F}_{\mathrm{E}} \mathrm{O}_{2}$, resulting in underestimation of $\mathrm{VO}_{2}$ (Beaver et al., 1973; Noguchi et al., 1982; Hughson et al., 1991). Conversely, overestimation of delay time results in underestimation of $\mathrm{O}_{2}$ and overestimation of $\mathrm{VO}_{2}$ (Beaver et al., 1973; Noguchi et al., 1982; Hughson et al., 1991). This limitation can be overcome by the use of a mixing chamber, were a representative microsample of each breath is temporally stored and mixed with previous samples before analysis (Overstreet et al., 2017). A new portable metabolic cart (COSMED K5) has been marketed with the option of measuring using either $\mathrm{B} \times \mathrm{B}$ or using a microproportional sampling averaging method. However, the accuracy and reliability of the COSMED K5 remains unknown.

Therefore, the purpose of this study was to determine the accuracy of COSMED K5 by comparison with a stationary metabolic cart at rest and during submaximal cycling exercise. Another aim was to measure the reliability of K5 for the assessment of energy expenditure during prolonged walks in the field. Walking rather than running was chosen to avoid potential artifacts due to mask displacement and to reduce thermal strain, so the subjects will not need to stop to remove the mask and drink. Since the validity of the Vyntus CPX remains unknown, a final aim was to determine the validity of Vyntus CPX using a butane combustion test.

\section{MATERIALS AND METHODS}

\section{Participants}

Two different studies were carried out to assess validity and reliability on two different groups separately. Sixteen Caucasian physically active volunteers (3 women and 13 men), between 19 and 32 years old, volunteered to participate in the validation study (Table 1). Another fourteen Caucasian physically active volunteers ( 3 women and 11 men), between 20 and 43 years old, agreed to participate in the reliability study (Table 1). All volunteers provided their written consent after being informed about the risks and benefits of the study, which was approved by the ethical committee of the University Hospital Dr. Negrin (Ref. 140187). All subjects were requested not to exercise and to refrain from drinking alcohol and beverages containing caffeine
TABLE 1 | Descriptive characteristics of K5 validation subjects (resting metabolic rate and exercise tests).

\begin{tabular}{lccccc}
\hline & \multicolumn{2}{c}{ Validation study $(n=16)$} & & \multicolumn{2}{c}{ Reliability study $(n=14)$} \\
\cline { 2 - 3 } \cline { 5 - 6 } Parameter & Mean \pm SD & Range & & Mean \pm SD & Range \\
\hline Age (years) & $23.3 \pm 3.4$ & $19.0-32.0$ & $25.4 \pm 6.5$ & $20.9-43.1$ \\
Weight $(\mathrm{kg})$ & $72.3 \pm 10.3$ & $61.0-96.3$ & $70.6 \pm 10.6$ & $55.9-89.3$ \\
Height $(\mathrm{cm})$ & $175.4 \pm 7.4$ & $162.2-185.0$ & $174.2 \pm 7.6$ & $163.8-188.3$ \\
BMl $\left(\mathrm{kg} / \mathrm{m}^{2}\right)$ & $23.4 \pm 2.5$ & $20.7-29.1$ & $23.1 \pm 2.2$ & $19.7-27.2$ \\
\hline
\end{tabular}

Values are means \pm standard deviation (SD). BMI, body mass index.

or taurine during the $48 \mathrm{~h}$ preceding the tests, as well as to eat a similar dinner the night before the tests.

\section{General Procedures}

Subjects reported to the laboratory between 7:00 and 9:30 A.M., following a 12-h overnight fast. Upon arrival, their body weight and height were measured to the nearest $0.1 \mathrm{~kg}$ and $0.1 \mathrm{~cm}$, respectively. Measurements were performed while subjects wore light clothes and no shoes using a balance scale (Seca, Hamburg, Germany) calibrated using certified calibration masses of class M1 (Scheck, Germany).

The validity of the COSMED K5 was determined by comparison with the Vyntus CPX (Jaeger-CareFusion, Höchberg, Germany) both at rest and during submaximal exercise on a cycle ergometer (Corival, Lode, Netherlands). Both metabolic carts were equipped with relatively new (less than 3 months old) oxygen fuel cells). Before the measurements both devices were warmed up for a minimum of $15 \mathrm{~min}$ calibrated with highgrade calibration gases provided by the manufacturers and by pumping gas with a $3 \mathrm{~L}$ calibration syringe through the flow meters, following the recommendations of the manufacturers. Mask size was individually fitted prior to the first test and the same size was maintained for subsequent trials.

\section{Validation Study}

For this purpose, subjects were instrumented with the Vyntus or COSMED facemask, in random order. The Vyntus was operated $\mathrm{BxB}$ and the COSMED $\mathrm{K} 5$ in $\mathrm{BxB}$ and mixing chamber modes. After arrival, subjects rested awake in the supine position during the next $60 \mathrm{~min}$ on a comfortable laboratory stretcher provided with a pillow, while their resting metabolic rate (RMR) was determined with both metabolic carts. Subjects were instructed to lie motionless and avoid talking during the measurement, which was carried out in a well-ventilated room while maintaining a quiet environment. The ergospirometric values recorded between the $20^{\text {th }}$ and $30^{\text {th }}$ min were averaged and used as representative of the metabolic cart tested first. During the following $5 \mathrm{~min}$ the device was changed in case the measurements started with the Vyntus, or switched from $\mathrm{B} \times \mathrm{B}$ to mixing chamber if the first device tested was the COSMED K5 and then to Vyntus. Thus, 10 min periods were collected with each device, with the first measurements starting after at least $20 \mathrm{~min}$ of comfortable rest in the supine position. A new full calibration (gas and flow) was done before switching systems. 
Then the volunteers performed two bouts of exercise on the cycle ergometer at $60 \mathrm{~W}$ for $10 \mathrm{~min}$, followed by $6 \mathrm{~min}$ at $130 \mathrm{~W}$ (women) or $160 \mathrm{~W}$ (men), keeping the pedaling rate at $80 \mathrm{rpm}$. These intensities were chosen to test the $\mathrm{K} 5$ at a low exercise intensity eliciting $\mathrm{VO}_{2}$ values similar to those observed during brisk walking (i.e., $\sim 6 \mathrm{~km} / \mathrm{h}$ ) (van der Walt and Wyndham, 1973), as well to a moderate exercise intensity eliciting a $\mathrm{VO}_{2}$ value close to the $\mathrm{VO}_{2 \text { max }}$ observed in sedentary populations (Edvardsen et al., 2013). To reduce potential carryover effects when changing from one metabolic cart to the other and to allow the assessment of substrate oxidation by indirect calorimetry, the highest load was chosen to elicit RER values close to 1.00. This sequence was repeated in random order while data were collected with the Vyntus, the COSMED K5 set on the $\mathrm{B} \times \mathrm{B}$ and mixing-chamber modes allowing a 20-min rest period between the bouts. Seat and handlebar adjustments were fit to the subject specifications and remained unchanged during all bouts.

\section{Reliability Study}

The reliability of the COSMED K5 was assessed by measuring ergospirometric variables and the energy expenditure during prolonged walks $(13 \mathrm{~km})$, which were repeated two times at least 4 days apart, with the device set in the mixing chamber mode. These tests were performed at the same time of day on non-raining days, and subjects were requested to wear similar clothing and the same walking shoes for the two trials. The walking route was relatively flat; including land and concrete sidewalks sections. The walking speed was maintained close to $5 \mathrm{~km} / \mathrm{h}$, using a Garmin Forerunner 210 (Garmin International Inc., Olathe, KS, United States) with GPS. The heart rate was measured with a Garmin Sensor connected to the K5. All subjects were weighted immediately before and after walking (SECA 869, Hamburg, Germany) while wearing all equipment and clothes. The scale was calibrated with certified calibration masses of class M1.

\section{Energy Expenditure}

Energy expenditure was calculated from $\mathrm{VO}_{2}$ and $\mathrm{VCO}_{2}$ data, assuming a negligible contribution of protein oxidation as previously reported (Peronnet and Massicotte, 1991).

\section{Validation of Vyntus CPX by Burning Butane}

The combustion of butane $\left(2 \mathrm{C}_{4} \mathrm{H}_{10}+13 \mathrm{O}_{2} \rightarrow 8 \mathrm{CO}_{2}+10\right.$ $\mathrm{H}_{2} \mathrm{O}+$ heat) has a respiratory quotient of 0.615 (8/13). Thus, we built an air-tight Plexiglas box $(70 \mathrm{~cm} \times 50 \mathrm{~cm} \times 50 \mathrm{~cm})$ with two $3.05 \mathrm{~cm}$ circular openings. One opening was connected to a 3-L calibration syringe (Hans Rudolf, Shawnee, KS) and in the other the turbine of the Vyntus with the sample lines for gas analysis was placed. Inside the Plexiglas box, a small butane burner was ignited while a 5 liter stainless steel cooking pot was placed on top filled with $0.5 \mathrm{~L}$ of water and ice up to the top, to dissipate the heat generated by the butane combustion. Three different burning intensities were used to simulate low, medium and very high exercise intensity. Within $5 \mathrm{~s}$ after the ignition of the butane burner, air was pumped in and out continuously using the calibration syringe, adjusting the stroke rate between 15 and 80 strokes/min until an almost "steady state" was reached, as reflected by the $\mathrm{F}_{\mathrm{E}} \mathrm{O}_{2}$ and $\mathrm{F}_{\mathrm{E}} \mathrm{CO}_{2}$. The pumping rate was then maintained for $2 \mathrm{~min}$. Butane combustion data were averaged every $10 \mathrm{~s}$ to determine the precision of the metabolic cart, and the coefficient of variation (CV) determined for a set of 5-6 consecutive averages with steady ventilation. The ventilation was considered steady when consecutive values differ by less than $10 \%$. Some variability in ventilation was unavoidable since the air was pumped manually, although always by the same operator.

\section{Statistical Analysis}

Data are reported as the mean $( \pm S D)$, unless otherwise stated. Values were checked for normal distribution using the ShapiroWilks test. The agreement between methods was assessed by determining the bias in absolute values and as a percentage of the measured value with the reference method (Vyntus) and the corresponding limit of agreement upper limit of agreement $($ ULA $)=$ bias $+1.96 \times S D$; lower limit of agreement $(\mathrm{LLA})=$ bias $-1.96 \times S D$. In addition, the agreement between methods was further examined by determining the Concordance Correlation Coefficient (CCC; Lin, 1989). The accuracy was evaluated by determining the differences between the mean values obtained with each method using Student $t$-test. The reliability of COSMED K5 measurements was assessed by determining the CV as described by Forkman (2007). Finally, the relationship between $\mathrm{VO}_{2}$ and $\mathrm{VCO}_{2}$ during butane combustion at different rates was assessed by the correlation coefficient of Pearson using 10-s averaged data. A $P$-value $\leq 0.05$ was considered to be statistically significant. All statistical analyses were performed using IBM SPSS v.21.0 for Mac Computers (IBM, New York, United States).

\section{RESULTS}

\section{In vitro Validation of Vyntus}

We used three different levels of combustion to simulate low, medium, and very high exercise intensities (Supplementary Table 1). The corresponding $\mathrm{VO}_{2}$ values were $0.788,1.314$, and $6.395 \mathrm{~L} / \mathrm{min}$ and the associated RQ values $0.624,0.608$, and 0.619 , respectively. The RQ deviation from the theoretical value for the combustion of butane $(0.615)$ were $1.5,-1.1$, and $0.7 \%$, respectively. The CV of RQ for 5-6 consecutive $10 \mathrm{~s}$ averaged-intervals with similar ventilation was always below $0.5 \%$. $\mathrm{VO}_{2}$ during butane combustion was closely related to $\mathrm{VCO}_{2}(r=0.9999)$.

\section{Accuracy and Precision}

During measurements at rest and $60 \mathrm{~W}$ Vyntus and COSMED $\mathrm{K} 5(\mathrm{~B} \times \mathrm{B})$ reported similar mean $\mathrm{VO}_{2}, \mathrm{VCO}_{2}, \mathrm{RER}$, and energy expenditure values (Supplementary Tables 2, 3 and Figures 14). Nevertheless, compared to Vyntus, COSMED K5 operated in mixing chamber mode (Mix) overestimated $\mathrm{VO}_{2}$ by 13.4 and $5.8 \%$, at rest and $60 \mathrm{~W}$, respectively (Supplementary Table 2). Both Vyntus and COSMED K5 (Mix) reported similar $\mathrm{V}_{\mathrm{E}}$ and 


\section{Bland and Altman plots of ergospirometric variables: resting supine}

Vyntus - COSMED K5 (BxB)

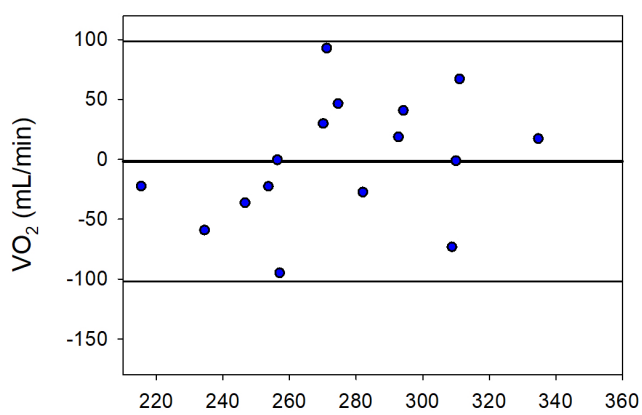

Mean of Vyntus and $\mathrm{K} 5(\mathrm{BxB}) \mathrm{VO}_{2}(\mathrm{~mL} / \mathrm{min})$

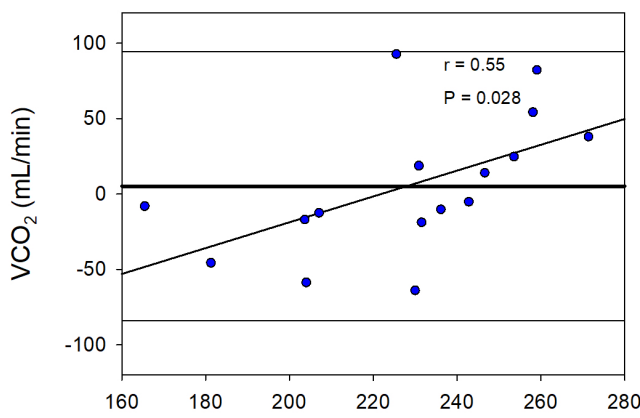

Mean of $\mathrm{Vyntus}$ and $\mathrm{K} 5(\mathrm{BxB}) \mathrm{VCO}_{2}(\mathrm{~mL} / \mathrm{min})$
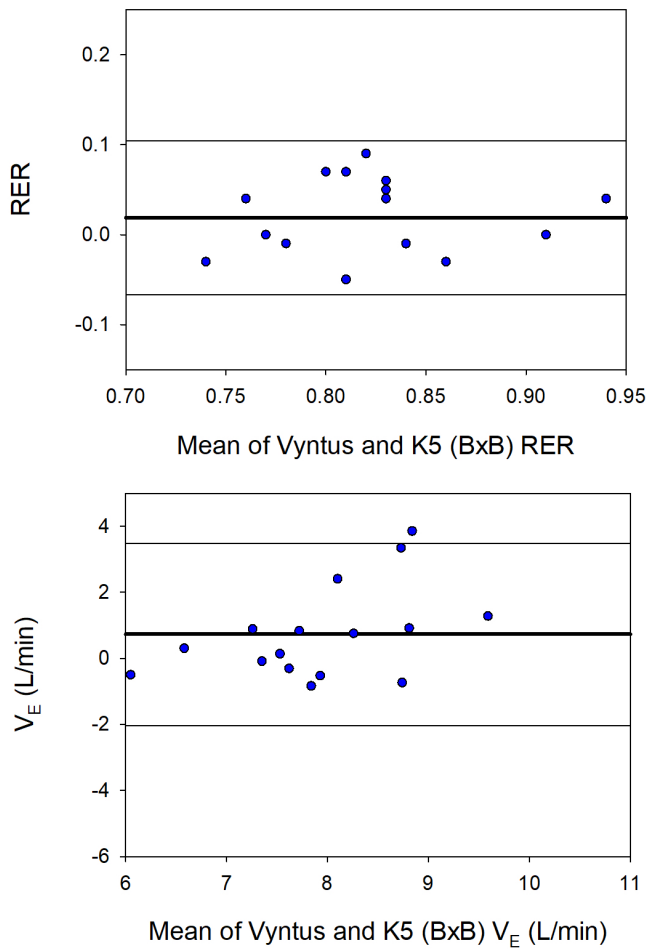

Vyntus - COSMED K5 (Mix)

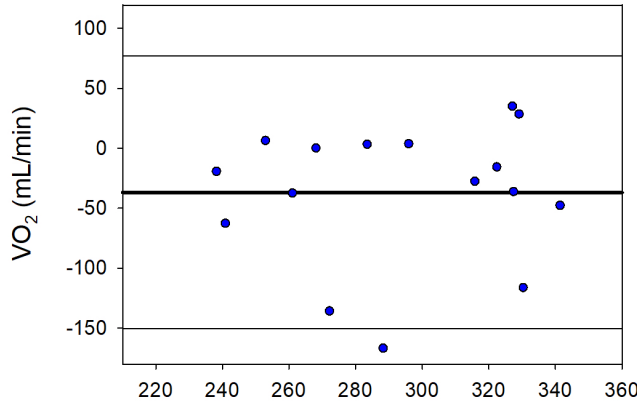

Mean of Vyntus and $\mathrm{K} 5$ (Mix) $\mathrm{VO}_{2}(\mathrm{~mL} / \mathrm{min})$
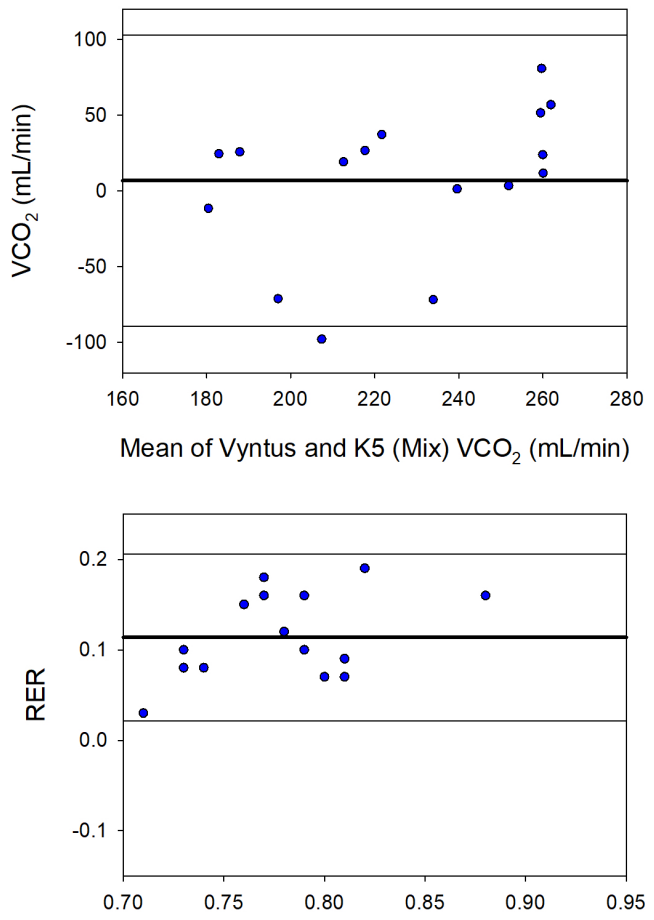

Mean of Vyntus and K5 (Mix) RER

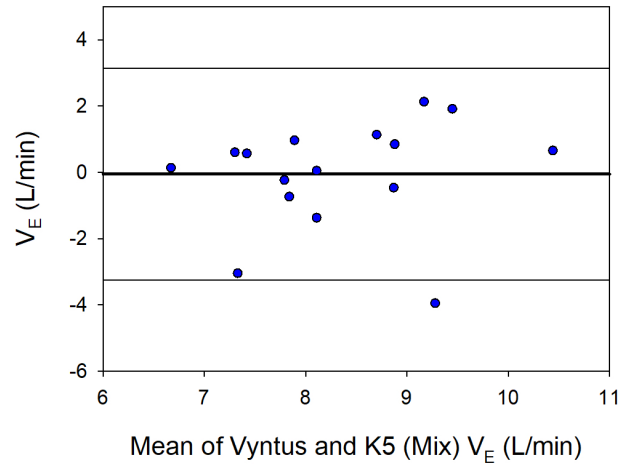

FIGURE 1 | Agreement between Vyntus (used as a reference stationary metabolic cart) and COSMED K5 operated Breath-by-Breath (BxB) and in Mixing Chamber (Mix) modes during resting measurements for oxygen uptake $\left(\mathrm{VO}_{2}\right)$, carbon dioxide production $\left(\mathrm{VCO}_{2}\right)$, respiratory exchange ratio (RER) and pulmonary ventilation $\left(V_{E}\right) \cdot N=16$. 


\section{Bland and Altman plots of ergospirometric variables: resting supine}

Vyntus - COSMED K5 (BxB)

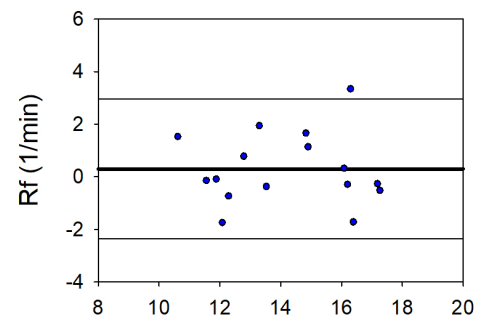

Mean of Vyntus and K5 (BxB) Rf (1/min)
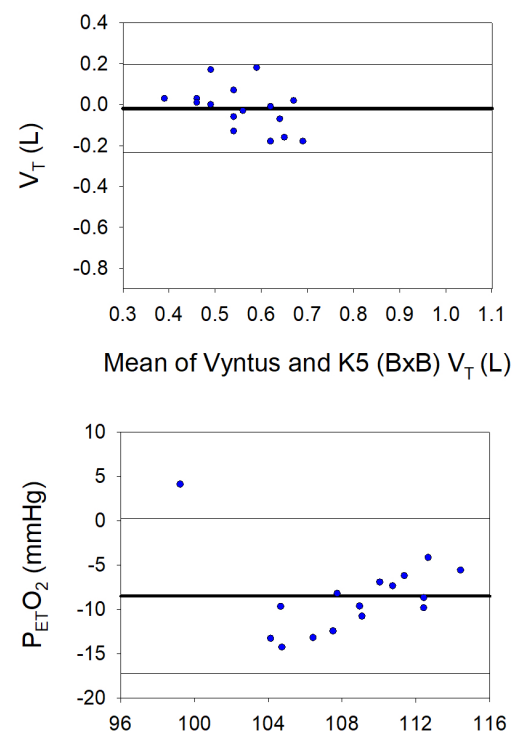

Mean of Vyntus and $\mathrm{K} 5(\mathrm{BxB}) \mathrm{P}_{\mathrm{ET}} \mathrm{O}_{2}(\mathrm{mmHg})$

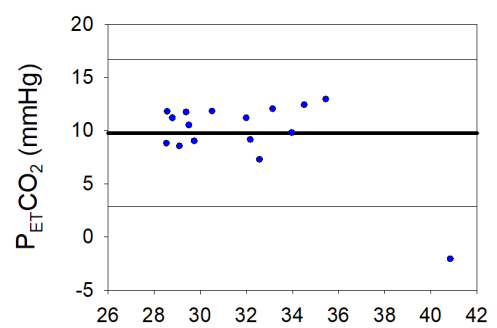

Mean of Vyntus and $\mathrm{K} 5(\mathrm{BxB}) \mathrm{P}_{\mathrm{ET}} \mathrm{CO}_{2}(\mathrm{mmHg})$

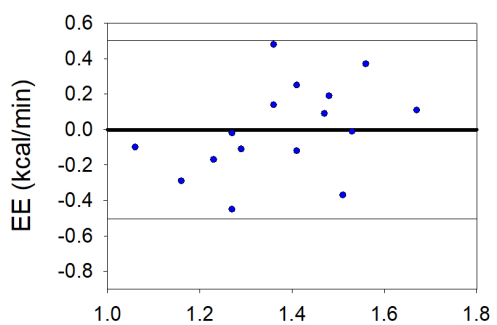

Mean of Vyntus and K5 (BxB) EE (kcal/min)
Vyntus - COSMED K5 (Mix)

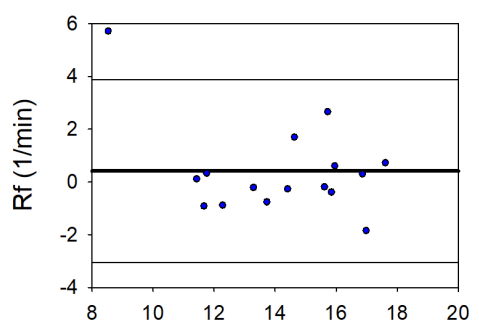

\section{Mean of Vyntus and K5 (Mix) Rf (1/min)}

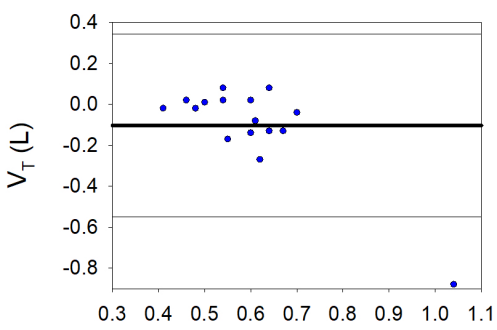

Mean of Vyntus and K5 (Mix) $\mathrm{V}_{\mathrm{T}}(\mathrm{L})$

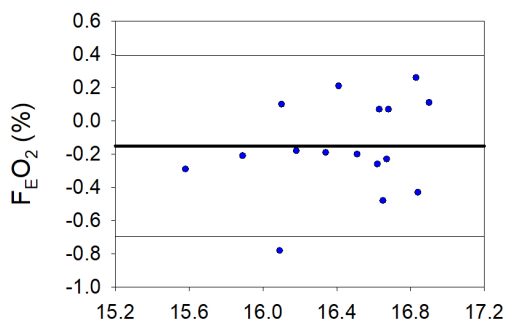

Mean of Vyntus and K5 (Mix) $\mathrm{F}_{\mathrm{E}} \mathrm{O}_{2}(\%)$

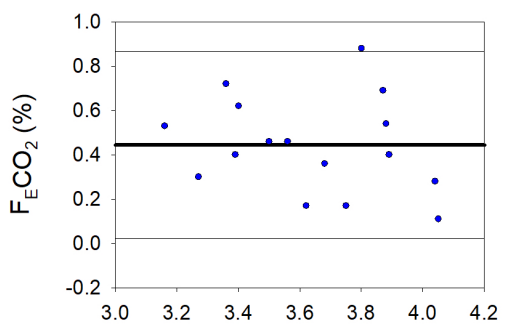

Mean of Vyntus and $\mathrm{K} 5$ (Mix) $\mathrm{F}_{\mathrm{E}} \mathrm{CO}_{2}(\%)$

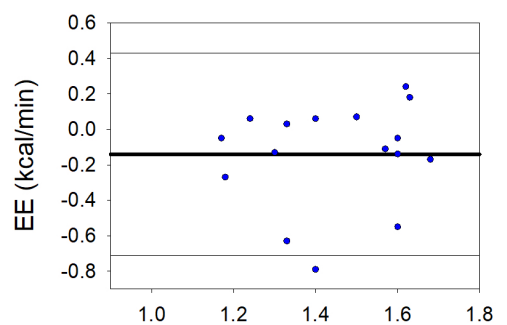

Mean of Vyntus and K5 (Mix) EE (kcal/min)

FIGURE 2 | Agreement between Vyntus (used as a reference stationary metabolic cart) and COSMED K5 operated Breath-by-Breath (BxB) and in Mixing Chamber (Mix) modes during resting measurements for respiratory frequency $(\mathrm{Rf})$, tidal volume $\left(\mathrm{V}_{\mathrm{T}}\right)$, end-tidal $\mathrm{O}_{2}$ pressure $\left(\mathrm{P}_{E T} \mathrm{O}_{2}\right)$, end-tidal $\mathrm{CO}_{2} \mathrm{Pressure}\left(\mathrm{P}_{\mathrm{ET}} \mathrm{CO}_{2}\right)$, and energy expenditure (EE). $N=16$. 


\section{Bland and Altman plots of ergospirometric variables: exercise at $60 \mathrm{~W}$}
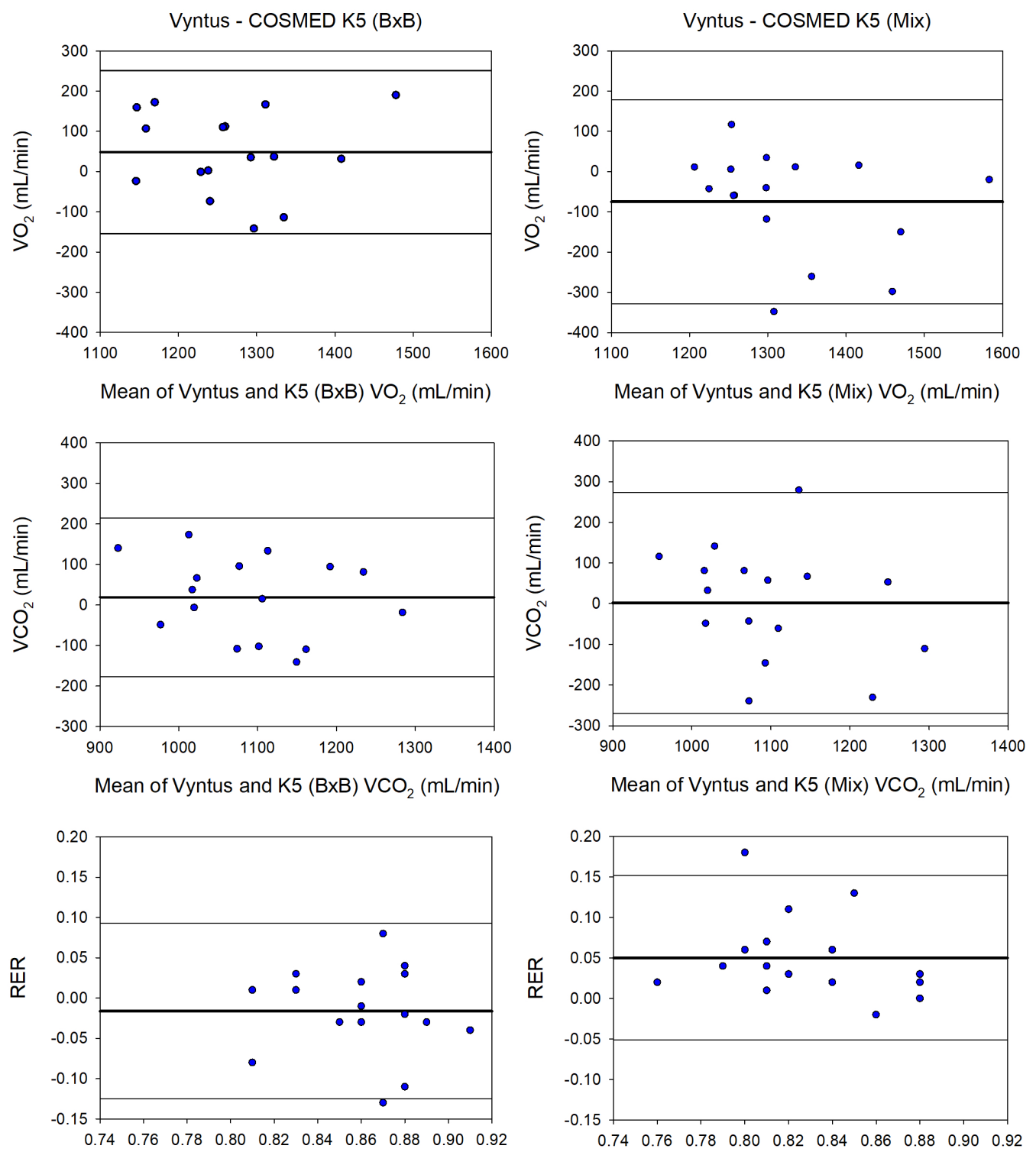

Mean of Vyntus and K5 (BxB) RER
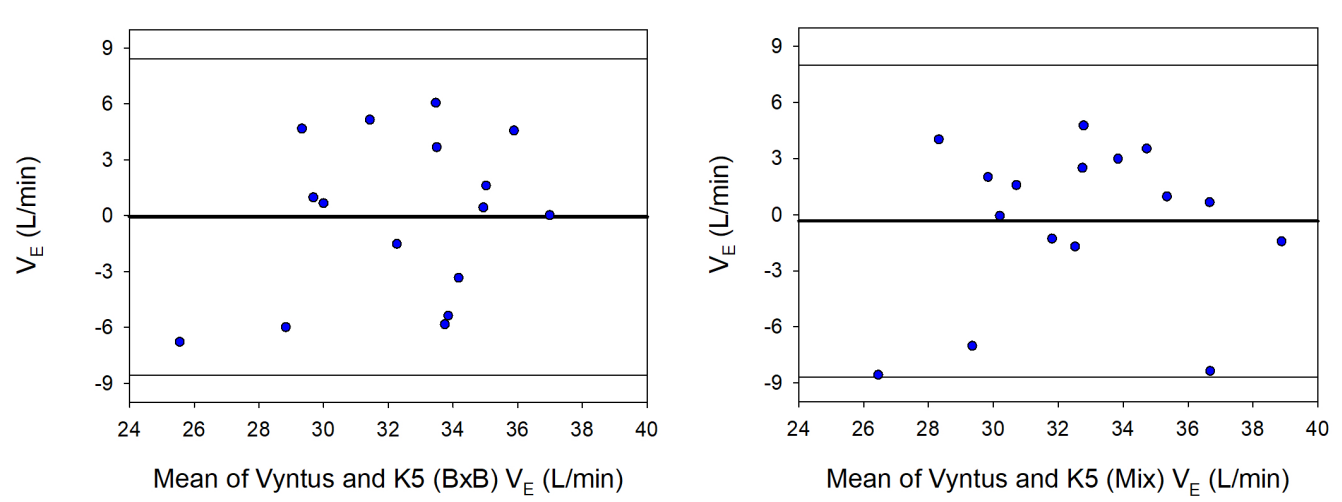

FIGURE 3 | Agreement between Vyntus (used as a reference stationary metabolic cart) and COSMED K5 operated Breath-by-Breath (B×B) and in Mixing Chamber (Mix) modes during low-intensity exercise (6OW) for $\mathrm{VO}_{2}, \mathrm{VCO}_{2}$, RER, and pulmonary ventilation $\left(\mathrm{V}_{\mathrm{E}}\right) \cdot \mathrm{N}=16$. 


\section{Bland and Altman plots of ergospirometric variables: exercise at $60 \mathrm{~W}$}

Vyntus - COSMED K5 (BxB)

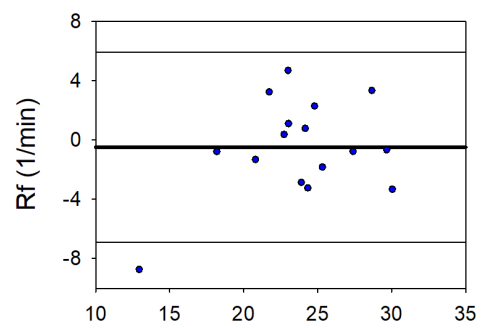

Mean of Vyntus and K5 (BxB) Rf $(1 / \mathrm{min})$

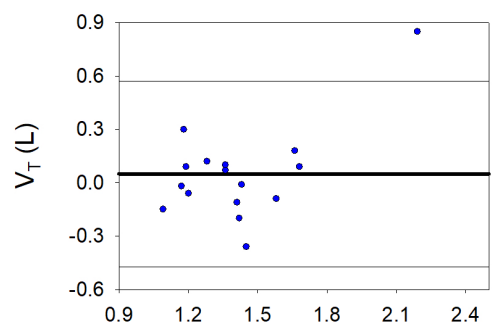

Mean of Vyntus and $\mathrm{K} 5(\mathrm{BxB}) \mathrm{V}_{\mathrm{T}}(\mathrm{L})$

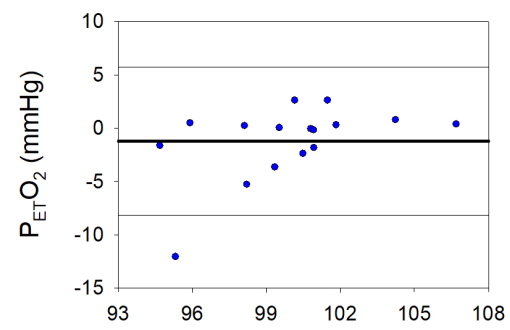

Mean of Vyntus and $\mathrm{K} 5(\mathrm{BxB}) \mathrm{P}_{\mathrm{ET}} \mathrm{O}_{2}(\mathrm{mmHg})$

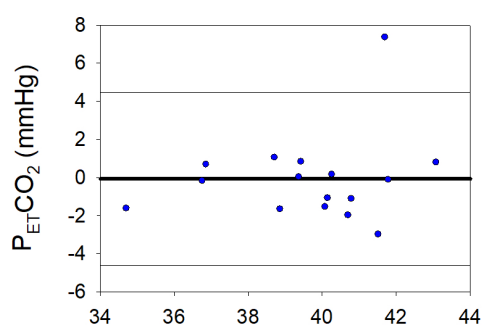

Mean of Vyntus and $\mathrm{K} 5(\mathrm{BxB}) \mathrm{P}_{\mathrm{ET}} \mathrm{CO}_{2}(\mathrm{mmHg})$

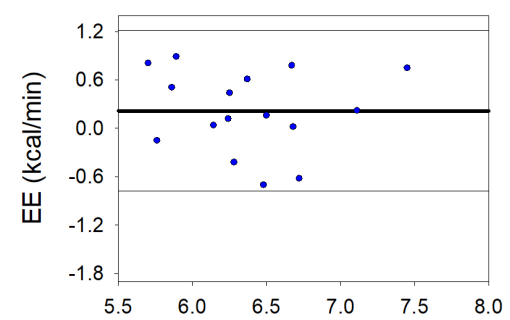

Mean of Vyntus and K5 (BxB) EE (kcal/min)
Vyntus - COSMED K5 (Mix)

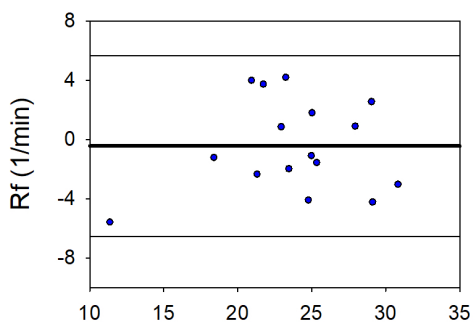

Mean of Vyntus and K5 (Mix) Rf (1/min)

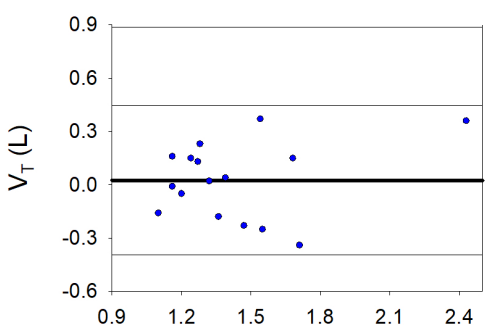

Mean of Vyntus and $\mathrm{K} 5$ (Mix) $\mathrm{V}_{\mathrm{T}}(\mathrm{L})$

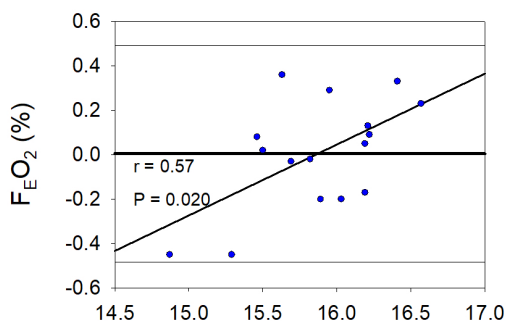

Mean of Vyntus and $\mathrm{K} 5$ (Mix) $\mathrm{F}_{\mathrm{E}} \mathrm{O}_{2}(\%)$

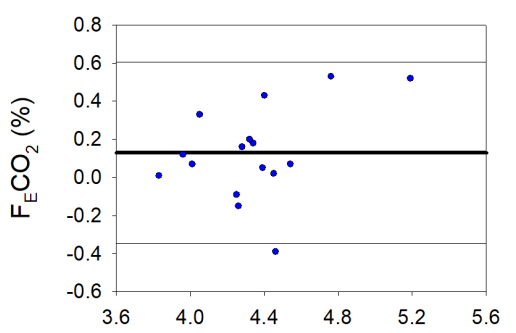

Mean of Vyntus and K5 (Mix) $\mathrm{F}_{\mathrm{E}} \mathrm{CO}_{2}(\%)$

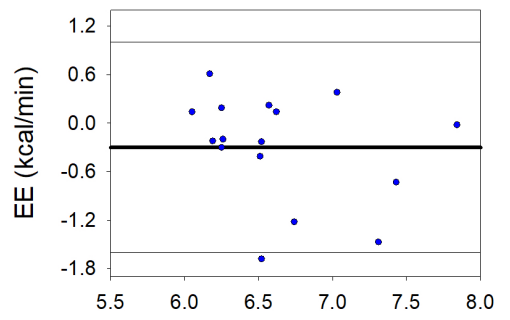

Mean of Vyntus and K5 (Mix) EE (kcal/min)

FIGURE 4 | Agreement between Vyntus (used as a reference stationary metabolic cart) and COSMED K5 operated Breath-by-Breath (BxB) and in Mixing Chamber (Mix) modes during low-intensity exercise for respiratory frequency $\left(\mathrm{R} f\right.$ ), tidal volume $\left(\mathrm{V}_{\mathrm{T}}\right)$, end-tidal $\mathrm{O}_{2}$ pressure $\left(\mathrm{P}_{\mathrm{ET}} \mathrm{O}_{2}\right)$, expiratory $\mathrm{O}_{2}$ fraction $\left(\mathrm{F}_{E} \mathrm{O}_{2}\right)$, end-tidal $\mathrm{CO}_{2}$ pressure $\left(\mathrm{PET}_{\mathrm{ET}} \mathrm{CO}_{2}\right)$, expiratory $\mathrm{CO}_{2}$ fraction $\left(\mathrm{F}_{\mathrm{E}} \mathrm{CO}_{2}\right)$, and energy expenditure $(\mathrm{EE}) . \mathrm{N}=16$. 
Bland and Altman plots of ergospirometric variables: exercise at $130-160 \mathrm{~W}$
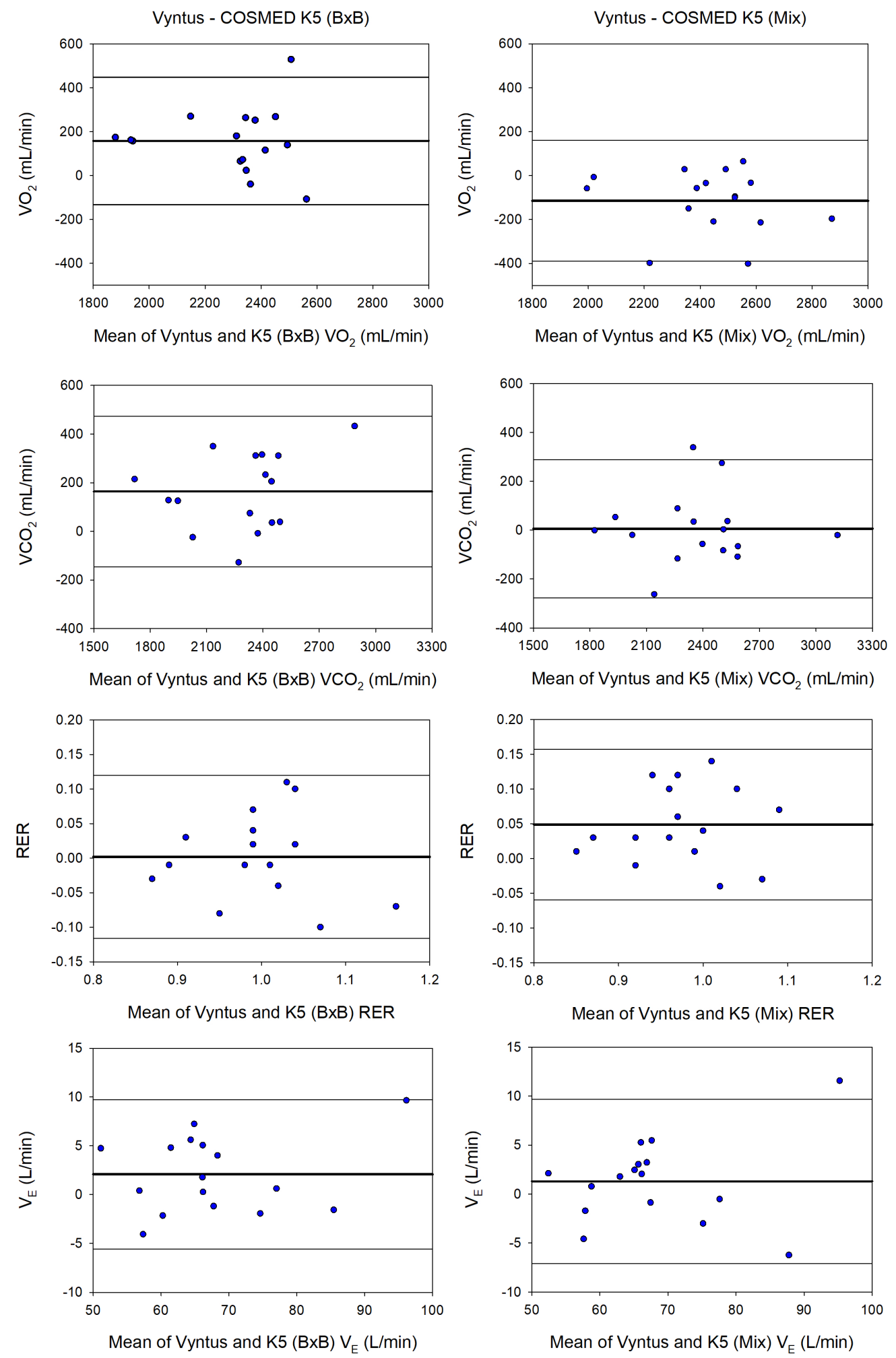

FIGURE 5 | Agreement between Vyntus (used as a reference stationary metabolic cart) and COSMED K5 operated Breath-by-Breath (BxB) and in Mixing Chamber (Mix) modes during moderate-intensity exercise (130-160 W) for oxygen uptake $\left(\mathrm{VO}_{2}\right)$, carbon dioxide production $\left(\mathrm{VCO}_{2}\right)$, respiratory exchange ratio $(\mathrm{RER})$ and pulmonary ventilation $\left(V_{E}\right) \cdot N=16$. 
Bland and Altman plots of ergospirometric variables: exercise at $130-160 \mathrm{~W}$

Vyntus - COSMED K5 (BxB)

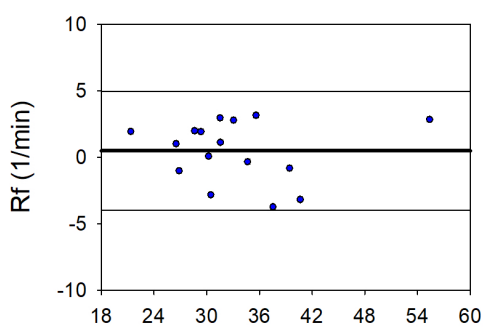

Mean of Vyntus and K5 (BxB) Rf (1/min)

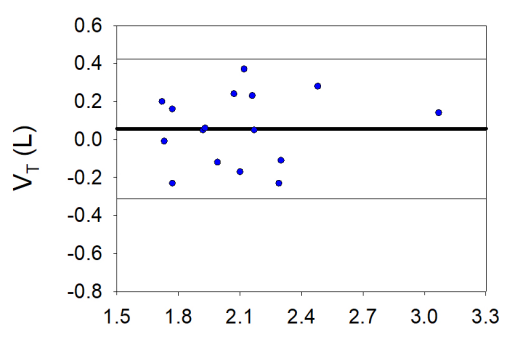

Mean of Vyntus and $\mathrm{K} 5(\mathrm{BxB}) \mathrm{V}_{\mathrm{T}}(\mathrm{L})$

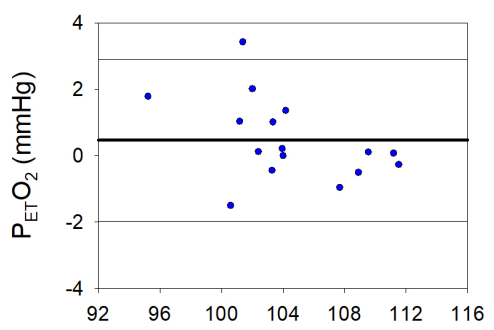

Mean of Vyntus and $\mathrm{K} 5(\mathrm{BxB}) \mathrm{P}_{\mathrm{ET}} \mathrm{O}_{2}(\mathrm{mmHg})$

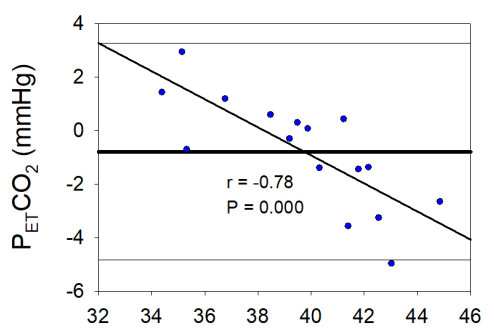

Mean of Vyntus and $\mathrm{K} 5(\mathrm{BxB}) \mathrm{P}_{\mathrm{ET}} \mathrm{CO}_{2}(\mathrm{mmHg})$

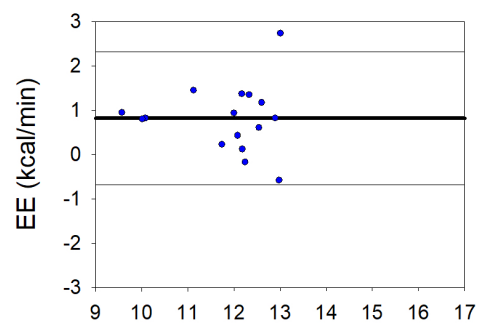

Mean of Vyntus and K5 (BxB) EE ( $\mathrm{kcal} / \mathrm{min})$
Vyntus - COSMED K5 (Mix)

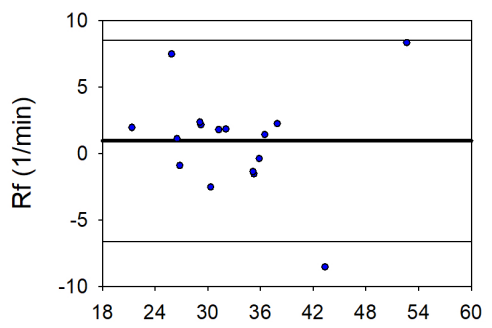

Mean of Vyntus and K5 (Mix) Rf (1/min)

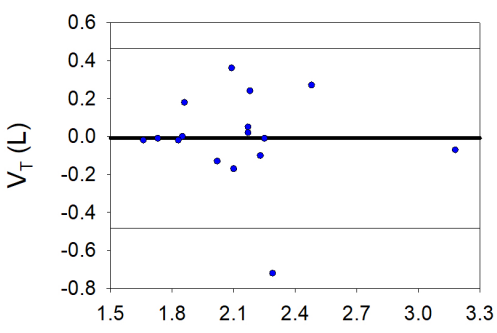

Mean of Vyntus and $\mathrm{K} 5$ (Mix) $\mathrm{V}_{\mathrm{T}}(\mathrm{L})$

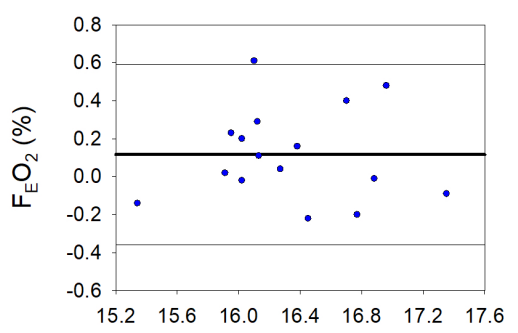

Mean of Vyntus and K5 (Mix) $\mathrm{F}_{\mathrm{E}} \mathrm{O}_{2}(\%)$

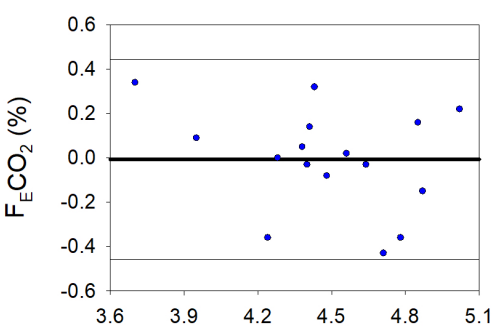

Mean of Vyntus and $\mathrm{K} 5$ (Mix) $\mathrm{F}_{\mathrm{E}} \mathrm{CO}_{2}(\%)$

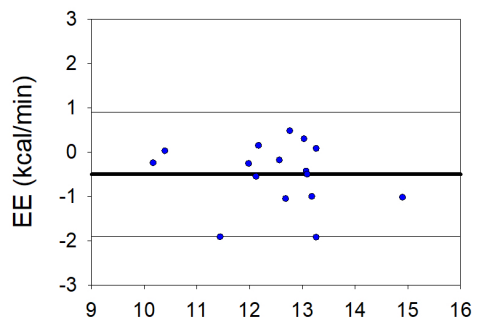

Mean of Vyntus and K5 (Mix) EE (kcal/min)

FIGURE 6 | Agreement between Vyntus (used as a reference stationary metabolic cart) and COSMED K5 operated Breath-by-Breath (BxB) and in Mixing Chamber (Mix) modes during moderate-intensity (130-160 W) exercise for respiratory frequency $(\mathrm{Rf})$, tidal volume $\left(\mathrm{V}_{\mathrm{T}}\right)$, end-tidal $\mathrm{O}_{2}$ pressure $\left(\mathrm{P}_{\mathrm{ET}} \mathrm{O}_{2}\right)$, expiratory $\mathrm{O}_{2}$ fraction $\left(\mathrm{F}_{\mathrm{E}} \mathrm{O}_{2}\right)$, end-tidal $\mathrm{CO}_{2}$ pressure $\left(\mathrm{PETCO}_{2}\right)$, expiratory $\mathrm{CO}_{2}$ fraction $\left(\mathrm{F}_{\mathrm{E}} \mathrm{CO}_{2}\right)$, and energy expenditure $(\mathrm{EE}) . \mathrm{N}=16$. 
$\mathrm{VCO}_{2}$ values. Consequently, COSMED K5 (Mix) underestimated RER by 13.8 and $5.8 \%$, at rest and at $60 \mathrm{~W}$, respectively.

At the highest intensity $(130 \mathrm{~W}$ and $160 \mathrm{~W}$ in women and men, respectively) COSMED $\mathrm{K} 5(\mathrm{~B} \times \mathrm{B})$ underestimated $\mathrm{VO}_{2}$ and $\mathrm{VCO}_{2}$ by 6.6 and $6.9 \%$, respectively, due to a $3.0 \%$ underestimation of $\mathrm{V}_{\mathrm{E}}(\mathrm{B} \times \mathrm{B})$ combined with $1.8 \% \mathrm{~F}_{\mathrm{E}} \mathrm{O}_{2}$ overestimation and $5.1 \%$ $\mathrm{F}_{\mathrm{E}} \mathrm{CO}_{2}$ underestimation by COSMED K5 (B×B) (Supplementary Table 3 and Figures 5, 6). This resulted in a 6.6\% underestimation of energy expenditure by COSMED K5 $(\mathrm{B} \times \mathrm{B})$. Nevertheless, there was an excellent agreement between methods in RER and fat oxidation, while COSMED underestimated carbohydrate oxidation by $6.9 \%$ (Supplementary Table 3 ).

COSMED K5 (Mix) overestimated $\mathrm{VO}_{2}$ during exercise by 5.8 and $4.8 \%$, at $60 \mathrm{~W}$ and the highest intensity, respectively. Consequently, COSMED K5 (Mix) overestimated energy expenditure by $4.1 \%$. Since $\mathrm{VCO}_{2}$ was accurately measured during exercise by COSMED K5 (Mix), COSMED K5 (Mix) underestimated the RER by 5.8 and $4.8 \%$, at $60 \mathrm{~W}$ and the highest intensity, respectively, causing a marked overestimation of fat oxidation (Supplementary Table 3).

\section{COSMED K5 Breath-by-Breath Compared With the Mixing Chamber Mode}

Compared to $\mathrm{B} \times \mathrm{B}$, the mixing chamber mode overestimated $\mathrm{VO}_{2}$ by $12.7 \%$ at rest (Supplementary Table 4 ). This bias in the assessment of resting $\mathrm{VO}_{2}$ is mostly explained by a $10.4 \% \mathrm{~V}_{\mathrm{E}}$ overestimation in Mix mode. However, $\mathrm{VCO}_{2}$ was accurately measured due to the compensation of the overestimation of $\mathrm{V}_{\mathrm{E}}$ by an underestimation of $\mathrm{F}_{\mathrm{E}} \mathrm{CO}_{2}$ in Mix mode. Consequently, the RER was underestimated by $11.8 \%$ and energy expenditure by $10.1 \%$ in Mix mode.

During exercise the Mix mode the $\mathrm{K} 5$ overestimated $\mathrm{VO}_{2}$ by 9.9 and $12.3 \%$ at $60 \mathrm{~W}$ and the highest load, respectively (Supplementary Table 5). This was explained by a 2.2 and $2.4 \%$ $\mathrm{F}_{\mathrm{E}} \mathrm{O}_{2}$ underestimation, respectively. At $60 \mathrm{~W}$, there was no bias in the assessment of $\mathrm{VCO}_{2}$, but it was overestimated by $7.1 \%$ at the highest intensity by the Mix mode, resulting in 7.5 and $4.7 \%$ underestimation of the RER at $60 \mathrm{~W}$ and the highest load, respectively. Consequently, the Mix mode overestimated energy expenditure by 8.3 and $11.5 \%$ at $60 \mathrm{~W}$ and highest load, respectively.

\section{Reliability}

The COSMED K5 had excellent reliability during the field tests (Supplementary Table 6), despite small changes in walking speed, starting weight, and environmental conditions (Supplementary Table 7). Total energy expenditure per Km was determined with a $\mathrm{CV}$ for repeated measurements of $4.5 \%$ (CI: $3.2-6.9 \%$ ) and a CCC of 0.91 , similar to the variability of $\mathrm{VO}_{2}$. This high reproducibility was explained by the low variation of $\mathrm{F}_{\mathrm{E}} \mathrm{O}_{2}$ measurements, which had a $\mathrm{CV}$ of $0.9 \%$ (CI: $0.7-1.5 \%$ ) combined with a slightly greater variability of $\mathrm{F}_{\mathrm{E}} \mathrm{CO}_{2}, \mathrm{~V}_{\mathrm{E}}, \mathrm{VCO}_{2}$, and RER.

\section{DISCUSSION}

In the present investigation, the Vyntus CareFusion metabolic cart was used as the reference method. Although Vyntus is a relatively new metabolic cart and no data about its validity against the Douglas bag method is available, its precedent Oxycon Pro was proven to be valid (Foss and Hallen, 2005). Moreover, this has been confirmed for the Vyntus when cross-calibrated against the Vmax29 (Carlomagno et al., 2015). Our butane combustion tests have also shown that the Vyntus CPX can measure the stoichiometric respiratory quotient of butane combustion at low and very high $\mathrm{O}_{2}$ flow with unprecedented accuracy and precision. Besides, the present investigation shows that the new COSMED K5 portable ergospirometer is an instrument that reproduces accurately the values obtained with the Vyntus metabolic cart at rest and during low-intensity exercise when operated in the $\mathrm{B} \times \mathrm{B}$ mode. We have also demonstrated that the COSMED K5 is highly precise at low-intensity exercise even during more than $2 \mathrm{~h}$ of continuous operation.

In the $\mathrm{B} \times \mathrm{B}$ mode, the COSMED $\mathrm{K} 5$ measures resting and low-intensity exercise (approximately $5 \mathrm{METs}$ ) $\mathrm{VO}_{2}, \mathrm{VCO}_{2}$, RER, and energy expenditure with an accuracy similar to that of the Vyntus metabolic cart, which has been recently marketed by the CareFusion company as a new metabolic cart based on its predecessors JAEGER Oxycon Pro and SensorMedics ${ }^{\mathrm{TM}} \mathrm{Vmax}^{\mathrm{TM}}$ Encore. Nevertheless, at a higher exercise intensity equivalent to approximately 9 METs, COSMED $\mathrm{K} 5$ underestimates by $6-7 \% \mathrm{VO}_{2}$ and $\mathrm{VCO}_{2}$, mostly due to underestimation of $\mathrm{V}_{\mathrm{E}}$ and a small bias in the assessment of $\mathrm{F}_{\mathrm{E}} \mathrm{O}_{2}$ and $\mathrm{F}_{\mathrm{E}} \mathrm{CO}_{2}$.

Inclusion of a mixing chamber mode is the main innovation incorporated in the COSMED K5 compared to its predecessor $\left(\mathrm{K}_{4} \mathrm{~B}^{2}\right)$. In a stationary metabolic cart, the addition of a mixing chamber allows to mix the expiratory gases from 36 breaths (depending on the size of the mixing chamber and the tidal volume). This allows for a more accurate assessment of the $\mathrm{F}_{\mathrm{E}} \mathrm{O}_{2}$ and $\mathrm{F}_{\mathrm{E}} \mathrm{CO}_{2}$. Nevertheless, in a portable device the size of the mixing chamber is limited and only a fraction (proportional micro-sample) of the tidal volume is aspirated into the chamber for mixing with precedent breaths. However, our results demonstrate that at rest and during low exercise intensity, the mixing chamber is less accurate than the $\mathrm{B} \times \mathrm{B}$ mode. Since there was a good agreement in $\mathrm{V}_{\mathrm{E}}$ and $\mathrm{VCO}_{2}$ between the mixing chamber and the $\mathrm{B} \times \mathrm{B}$ modes of the COSMED $\mathrm{K} 5$, the divergence here observed in $\mathrm{VO}_{2}$ between these two modes is likely due to the impact that the assumption of a fixed $\mathrm{F}_{\mathrm{I}} \mathrm{O}_{2}(0.209)$ has on the calculation of $\mathrm{VO}_{2}$. At higher exercise intensities, the tidal volume increases and the impact of the facemask dead space on the $\mathrm{F}_{\mathrm{I}} \mathrm{O}_{2}$ is reduced, i.e., the actual $\mathrm{F}_{\mathrm{I}} \mathrm{O}_{2}$ becomes closer to the assumed by the COSMED $\mathrm{K} 5$ (0.209) reducing the bias in the assessment of $\mathrm{VO}_{2}$ at the highest exercise intensity. Our data also demonstrate that in the mixing chamber mode, the COSMED K5 measured the $\mathrm{F}_{\mathrm{E}} \mathrm{O}_{2}$ with similar accuracy as Vyntus, while in the $\mathrm{B} \times \mathrm{B}$ mode it overestimated the $\mathrm{F}_{\mathrm{E}} \mathrm{O}_{2}$ obtained with the Vyntus. Thus, when the aim of the study is to measure $\mathrm{VO}_{2}$ or substrate oxidation at high exercise intensities the mixing 
chamber mode is preferable. In contrast, measuring the resting RER with the COSMED K5 set in mixing chamber mode yields RER values close to 0.70 , a value that is too low for subjects that have been fasting only overnight (Compher et al., 2006). Thus, at rest and during low intensity exercise the $\mathrm{B} \times \mathrm{B}$ mode is more accurate.

Our data also indicate that the COSMED K5 performs at least as well as its predecessor COSMED K4B ${ }^{2}$ (Doyon et al., 2001; McLaughlin et al., 2001; Pinnington et al., 2001; Eisenmann et al., 2003; Duffield et al., 2004; Mc Naughton et al., 2005), while the addition of the mixing chamber mode allows more accurate assessments at high-intensity exercise.

\section{Precision of COSMED K5}

The precision of COSMED K5 was determined by using the mixing chamber mode during prolonged low intensity exercise in the field. Our data demonstrate that the COSMED K5 can assess $\mathrm{VO}_{2}$ and energy expenditure during prolonged walking with a $\mathrm{CV}$ below 5\%, i.e., performing at a similar level of precision as stationary metabolic carts (Carter and Jeukendrup, 2002; Crouter et al., 2006). It should be taken into consideration that this low CV was obtained despite small changes in body weight, environmental conditions, walking speed, and weight loss during the walks. Thus, even lower CVs may be achievable with the K5 under better controlled environmental conditions as during test carried out in laboratories. This level of precision exceeds that reported for its predecessor the $\mathrm{K}_{4} \mathrm{~B}^{2}$ for repeated walking measurements in separate days during treadmill walking (Darter et al., 2013; Howe et al., 2014) as well as during incremental exercise (Schrack et al., 2010; Brisswalter and Tartaruga, 2014).

\section{Accuracy and Precision of Vyntus CPX (Butane Combustion Tests)}

Combustion of fuels like ethanol (Cooper et al., 1991; Rising et al., 2015), methanol (Damask et al., 1982; Miodownik et al., 1998), propane (Melanson et al., 2010; Rising et al., 2015; Ismail, 2017), and butane (Nunn et al., 1989; Joosten et al., 2000) are considered gold-standard methods to validate indirect calorimeters. A common feature of precedent propane and butane combustion studies has been the use of only low combustion rates. In the present investigation we have used a similar methodology but using a broad range of combustion rates eliciting $\mathrm{VO}_{2}$ values spanning across the physiological $\mathrm{VO}_{2}$ values reachable by humans with varied fitness levels. In addition, our simulation generated respiratory variables mostly within the physiological range for humans. Importantly, our data

\section{REFERENCES}

Beaver, W. L., Wasserman, K., and Whipp, B. J. (1973). On-line computer analysis and breath-by-breath graphical display of exercise function tests. J. Appl. Physiol. 34, 128-132. doi: 10.1152/jappl.1973.34.1.128

Brehm, M. A., Harlaar, J., and Groepenhof, H. (2004). Validation of the portable VmaxST system for oxygen-uptake measurement. Gait Posture 20, 67-73. doi: 10.1016/S0966-6362(03)00097-3

Brisswalter, J., and Tartaruga, M. P. (2014). Comparison of COSMED'S FitMate and $\mathrm{K}_{4} \mathrm{~b}^{2}$ metabolic systems reliability during graded cycling exercise. Scand. J. Clin. Lab. Invest. 74, 722-724. doi: 10.3109/00365513.2014.930711 indicate that the Vyntus CPX metabolic cart is exceptionally accurate and precise measuring the stoichiometric RQ of butane combustion. This is only possible when $\mathrm{VO}_{2}$ and $\mathrm{VCO}_{2}$ are computed correctly from the inspired and expired $\mathrm{O}_{2}$ and $\mathrm{CO}_{2}$ fractions, even at high breathing frequencies (highest butane combustion rate) and despite differences in incurrent and excurrent airstreams (see Supplementary Table 1).

In summary, our data indicate that the COSMED $\mathrm{K} 5$ is an excellent portable metabolic cart which is almost as accurate as a state-of-art stationary metabolic cart, capable of measuring precisely energy expenditure in the field and showing a reliable performance during more than $2 \mathrm{~h}$ of continuous work. The mixing-chamber option allows for more accurate assessment of $\mathrm{VO}_{2}$ during exercise at relatively higher intensities, but is less accurate at low exercise intensities, and should not be used to measure resting energy expenditure.

\section{AUTHOR CONTRIBUTIONS}

JC, DM-A, and IP-S conceived and designed the experiments. IP-S, MM-R, CF, SP-R, VG-A, JJ-H, and DM-A performed the pre-testing, experimental preparation, and data collection. IP-S, SP-R, CF, and JC analyzed the data. IP-S and JC wrote the first draft of the manuscript. All co-authors edited and proofread the manuscript and approved the final version.

\section{FUNDING}

This study was financed by grants from the Ministerio de Economía y Competitividad (PI14/01509, DEP2015-71171-R, DEP2017-86409-C2-1-P and FEDER) and ProID2017010106.

\section{ACKNOWLEDGMENTS}

We offer special thanks to José Navarro de Tuero for his excellent technical assistance. The use of the brand name COSMED K5 is with the permission of the copyright holders COSMED.

\section{SUPPLEMENTARY MATERIAL}

The Supplementary Material for this article can be found online at: https://www.frontiersin.org/articles/10.3389/fphys. 2018.01764/full\#supplementary-material

Carlomagno, D., Bosio, A., Morelli, A., Tornaghi, M., Induni, M., and Rampinini, E. (2015). “Agreement between Vmax29 and the new breath-bybreath respiratory system Vyntus cpx during maximal incremental exercise," in Proceedings of the 20th Annual Congress of the European College of Sport Science, eds A. Radmann, S. Hedenborg, and E. Tsolakidis (Malmo: European College of Sport Science).

Carter, J., and Jeukendrup, A. E. (2002). Validity and reliability of three commercially available breath-by-breath respiratory systems. Eur. J. Appl. Physiol. 86, 435-441. doi: 10.1007/s00421-001-0572-2

Clemensen, P., Christensen, P., Norsk, P., and Gronlund, J. (1994). A modified photo- and magnetoacoustic multigas analyzer applied in gas exchange 
measurements. J. Appl. Physiol. 76, 2832-2839. doi: 10.1152/jappl.1994.76.6. 2832

Compher, C., Frankenfield, D., Keim, N., Roth-Yousey, L., and Evidence Analysis Working, G. (2006). Best practice methods to apply to measurement of resting metabolic rate in adults: a systematic review. J. Am. Diet. Assoc. 106, 881-903. doi: 10.1016/j.jada.2006.02.00

Cooper, B. G., Mclean, J. A., and Taylor, R. (1991). An evaluation of the Deltatrac indirect calorimeter by gravimetric injection and alcohol burning. Clin. Phys. Physiol. Meas. 12, 333-341.

Crouter, S. E., Antczak, A., Hudak, J. R., Dellavalle, D. M., and Haas, J. D. (2006). Accuracy and reliability of the ParvoMedics TrueOne 2400 and MedGraphics VO2000 metabolic systems. Eur. J. Appl. Physiol. 98, 139-151. doi: 10.1007/ s00421-006-0255-0

Damask, M. C., Weissman, C., Askanazi, J., Hyman, A. I., Rosenbaum, S. H., and Kinney, J. M. (1982). A systematic method for validation of gas exchange measurements. Anesthesiology 57, 213-218. doi: 10.1097/00000542-19820900000011

Darter, B. J., Rodriguez, K. M., and Wilken, J. M. (2013). Test-retest reliability and minimum detectable change using the $\mathrm{K}_{4} \mathrm{~b}^{2}$ : oxygen consumption, gait efficiency, and heart rate for healthy adults during submaximal walking. Res. Q. Exerc. Sport 84, 223-231. doi: 10.1080/02701367.2013.78472

Doyon, K. H., Perrey, S., Abe, D., and Hughson, R. L. (2001). Field testing of $\mathrm{VO}_{2}$ peak in cross-country skiers with portable breath-by-breath system. Can. J. Appl. Physiol. 26, 1-11. doi: 10.1139/h01-001

Duffield, R., Dawson, B., Pinnington, H. C., and Wong, P. (2004). Accuracy and reliability of a Cosmed $\mathrm{K}_{4} \mathrm{~b}^{2}$ portable gas analysis system. J. Sci. Med. Sport 7, 11-22. doi: 10.1016/S1440-2440(04)80039-2

Edvardsen, E., Scient, C., Hansen, B. H., Holme, I. M., Dyrstad, S. M., and Anderssen, S. A. (2013). Reference values for cardiorespiratory response and fitness on the treadmill in a 20- to 85-year-old population. Chest 144, 241-248. doi: $10.1378 /$ chest.12-1458

Eisenmann, J. C., Brisko, N., Shadrick, D., and Welsh, S. (2003). Comparative analysis of the Cosmed Quark $\mathrm{b}^{2}$ and $\mathrm{K} 4 \mathrm{~b}^{2}$ gas analysis systems during submaximal exercise. J. Sports Med. Phys. Fitness 43, 150-155.

Forkman, J. (2007). Statistical Inference for Coefficients of Variation Shared by Several Populations. Uppsala: Swedish University of Agricultural Sciences, 1-17.

Foss, O., and Hallen, J. (2005). Validity and stability of a computerized metabolic system with mixing chamber. Int. J. Sports Med. 26, 569-575. doi: 10.1055/s2004-821317

Howe, C. C., Matzko, R. O., Piaser, F., Pitsiladis, Y. P., and Easton, C. (2014). Stability of the $\mathrm{K}_{4} \mathrm{~b}^{2}$ portable metabolic analyser during rest, walking and running. J. Sports Sci. 32, 157-163. doi: 10.1080/02640414.2013.812231

Hughson, R. L., Northey, D. R., Xing, H. C., Dietrich, B. H., and Cochrane, J. E. (1991). Alignment of ventilation and gas fraction for breath-by-breath respiratory gas exchange calculations in exercise. Comput. Biomed. Res. 24, 118-128. doi: 10.1016/0010-4809(91)90024-Q

Ismail, M. A. (2017). Validation of a Propane Gas Calibration Device for Indirect Calorimetric Systems. Master thesis, Memorial University of Newfoundland, St. John's.

Joosten, K. F., Jacobs, F. I., Van Klaarwater, E., Baartmans, M. G., Hop, W. C., Merilainen, P. T., et al. (2000). Accuracy of an indirect calorimeter for mechanically ventilated infants and children: the influence of low rates of gas exchange and varying $\mathrm{F}_{\mathrm{I}} \mathrm{O}_{2}$. Crit. Care Med. 28, 3014-3018. doi: 10.1097/ 00003246-200008000-00056
Lin, L. I. (1989). A concordance correlation coefficient to evaluate reproducibility. Biometrics 45, 255-268. doi: 10.2307/2532051

Mc Naughton, L. R., Sherman, R., Roberts, S., and Bentley, D. J. (2005). Portable gas analyser Cosmed $\mathrm{K}_{4} \mathrm{~b}^{2}$ compared to a laboratory based mass spectrometer system. J. Sports Med. Phys. Fitness 45, 315-323.

McLaughlin, J. E., King, G. A., Howley, E. T., Bassett, D. R. Jr., and Ainsworth, B. E. (2001). Validation of the COSMED K4b $\mathrm{b}^{2}$ portable metabolic system. Int. J. Sports Med. 22, 280-284. doi: 10.1055/s-2001-13816

Melanson, E. L., Ingebrigtsen, J. P., Bergouignan, A., Ohkawara, K., Kohrt, W. M., and Lighton, J. R. (2010). A new approach for flow-through respirometry measurements in humans. Am. J. Physiol. Regul. Integr. Comp. Physiol. 298, R1571-R1579. doi: 10.1152/ajpregu.00055.2010

Miodownik, S., Melendez, J., Carlon, V. A., and Burda, B. (1998). Quantitative methanol-burning lung model for validating gas-exchange measurements over wide ranges of $\mathrm{F}_{\mathrm{I}} \mathrm{O}_{2}$. J. Appl. Physiol. 84, 2177-2182. doi: 10.1152/jappl.1998.84. 6.2177

Noguchi, H., Ogushi, Y., Yoshiya, I., Itakura, N., and Yamabayashi, H. (1982). Breath-by-breath $\mathrm{VCO}_{2}$ and $\mathrm{VO}_{2}$ required compensation for transport delay and dynamic response. J. Appl. Physiol. 52, 79-84. doi: 10.1152/jappl.1982. 52.1.79

Nunn, J. F., Makita, K., and Royston, B. (1989). Validation of oxygen consumption measurements during artificial ventilation. J. Appl. Physiol. 67, 2129-2134. doi: 10.1152/jappl.1989.67.5.2129

Overstreet, B. S., Bassett, D. R. Jr., Crouter, S. E., Rider, B. C., and Parr, B. B. (2017). Portable open-circuit spirometry systems. J. Sports Med. Phys. Fitness 57, 227-237. doi: 10.23736/S0022-4707.16.06049-7

Peronnet, F., and Massicotte, D. (1991). Table of nonprotein respiratory quotient: an update. Can. J. Sport Sci. 16, 23-29.

Pinnington, H. C., Wong, P., Tay, J., Green, D., and Dawson, B. (2001). The level of accuracy and agreement in measures of $\mathrm{F}_{\mathrm{E}} \mathrm{O}_{2}, \mathrm{~F}_{\mathrm{E}} \mathrm{CO}_{2}$ and $\mathrm{V}_{\mathrm{E}}$ between the Cosmed $\mathrm{K}_{4} \mathrm{~b}^{2}$ portable, respiratory gas analysis system and a metabolic cart. J. Sci. Med. Sport 4, 324-335. doi: 10.1016/S1440-2440(01)80041-4

Rising, R., Whyte, K., Albu, J., and Pi-Sunyer, X. (2015). Evaluation of a new whole room indirect calorimeter specific for measurement of resting metabolic rate. Nutr. Metab. 12:46. doi: 10.1186/s12986-015-0043-0

Schrack, J. A., Simonsick, E. M., and Ferrucci, L. (2010). Comparison of the Cosmed $\mathrm{K}_{4} \mathrm{~b}^{2}$ portable metabolic system in measuring steady-state walking energy expenditure. PLoS One 5:e9292. doi: 10.1371/journal.pone.0009292

van der Walt, W. H., and Wyndham, C. H. (1973). An equation for prediction of energy expenditure of walking and running. J. Appl. Physiol. 34, 559-563. doi: 10.1152/jappl.1973.34.5.559

Conflict of Interest Statement: The authors declare that the research was conducted in the absence of any commercial or financial relationships that could be construed as a potential conflict of interest.

Copyright (c) 2018 Perez-Suarez, Martin-Rincon, Gonzalez-Henriquez, Fezzardi, Perez-Regalado, Galvan-Alvarez, Juan-Habib, Morales-Alamo and Calbet. This is an open-access article distributed under the terms of the Creative Commons Attribution License (CC BY). The use, distribution or reproduction in other forums is permitted, provided the original author(s) and the copyright owner(s) are credited and that the original publication in this journal is cited, in accordance with accepted academic practice. No use, distribution or reproduction is permitted which does not comply with these terms. 